http://doi.org/10.35784/iapgos.2658

\title{
DEVELOPMENT OF A DEVICE FOR MEASURING AND ANALYZING VIBRATIONS
}

\author{
Anzhelika Stakhova, Volodymyr Kvasnikov \\ National Aviation University, Department of Computerized Electrical Systems and Technologies, Kiev, Ukraine
}

Abstract. It is known that vibration is generated to one degree or another by all moving parts of machines. Vibration processes arising in the process of functioning of machines and equipment are highly informative, reflecting the technical condition of many parts and assemblies quite fully. Therefore, the use of vibration diagnostics systems makes it possible to determine a defect even at the stage of inception, thereby excluding emergency stops of machinery. An urgent task is to create a vibration analysis device, which consists of a sensor for measuring vibration, the principle of operation of which is based on the use of a direct piezoelectric effect. The output signal of the sensor will go to a personal computer or any other device with the Windows operating system, where a spectral analysis of the measured vibration signal is carried out using a Matlab-based diagnostic program.

Keywords: up vibrations, defect, vibroacoustic parameters, vibration measurement

\section{OPRACOWANIE URZĄDZENIA DO POMIARU I ANALIZY DRGAŃ}

\begin{abstract}
Streszczenie. Wiadomo, że wibracje $w$ mniejszym lub większym stopniu sa generowane przez wszystkie ruchome części maszyn. Procesy wibracyjne powstające $w$ trakcie pracy maszyn $i$ urządzeń maja bardzo bogaty charakter informacyjny, w petni odzwierciedlając stan techniczny wielu części i zespołów. Dlatego zastosowanie systemów diagnostyki drganiowej pozwala na określenie usterki już na etapie jej powstania, wykluczając tym samym awaryjne zatrzymania maszyn. Pilnym zadaniem jest stworzenie urządzenia do analizy drgań, które składa się z czujnika do pomiaru drgań, którego zasada działania opiera się na wykorzystaniu bezpośredniego efektu piezoelektrycznego. Sygnat wyjściowy czujnika trafia do komputera osobistego lub innego urzadzenia z systemem operacyjnym Windows, gdzie analiza widmowa mierzonego sygnału drgań jest przeprowadzana za pomoca programu diagnostycznego opartego na Matlabie.
\end{abstract}

Slowa kluczowe: drgania, wady, parametry wibroakustyczne, pomiar drgań

\section{Introduction}

Modern development of technological equipment has led to the fact that machines and other devices of heavy construction have become an integral part of human everyday life. Continuous improvement of technical equipment accelerates the pace of work, as well as the load at which modern devices work. As a result, the parts used in these machines wear out faster. And failure of one part of the device can lead to breakage of other part or and, even, all mechanism.

Often such breakdowns are observed, after which the equipment becomes unsuitable for repair. It becomes necessary to replace equipment parts, and in some cases, even have to replace the entire mechanism. But modern equipment is equipped with the latest technological solutions, has a very high cost and expensive maintenance. Therefore, the task of ensuring the reliability of the equipment used, as well as to attract the latest technologies for diagnosing equipment becomes urgent.

Therefore, the equipment of each enterprise requires periodic inspection. This will prevent premature failure of the equipment, to predict the location of the defect before it is formed. Replace a part of a certain part of the machine or take the necessary measures to stop the development of the defect. It should be noted that the reason for the failure of the machine is the use of parts in which there was a defect during manufacture.

There are many methods of diagnosing equipment and one of the methods of modern diagnostics is vibration diagnostics. Vibration diagnostics is now widely used [2, 3, 8, 9], since vibration processes sufficiently fully reflect the technical condition of many parts and assemblies. Vibration diagnostic methods are aimed at detecting and identifying such malfunctions of the unit that affect its vibration.

It uses vibroacoustic processes in her work, which have a very large amount of information about the operation of the machine, about the condition of its parts. Thus at processing of the received signals the modern technological apparatus which allows to carry out inspection during work of the equipment, without its dismantling is used. Methods such as temperature control, lubricant analysis and others, with the right approach, are practically not required - they are replaced by vibration analysis. In addition, modern methods of information processing are used. These diagnostic methods are the most sensitive to changes in the vibration properties of the object of diagnosis under the influence of defects.
The introduction of modern computer technology into production makes it possible to process large volumes of measurement data, which significantly contributes to the development of modern methods of equipment maintenance with the search for new informative parameters, including maintenance based on the technical (actual) state [12]. It remains an urgent task to create a device for measuring and analyzing vibrations, with the search for a diagnostic parameter, which will be sensitive to the point of becoming more sensitive to the point of view of the reliability of control with a further elaborate diagnostic program based on Matlab.

\section{Diagnostic parameters}

Information about the status of the details of the object carries a certain signal. It can be of different physical nature, the main thing is that it contains information about the state of the object under study and is easy to read by a certain device. On the way from the formation of the defect to its receipt in a certain diagnostic apparatus, the signal undergoes many numerical transformations. As a result, its shape and physical nature change, but the information transmitted by this signal must remain unchanged. Otherwise, we will receive a signal that will carry false information about the state of the object. Such a signal will be of no use to us.

The defect can be detected and predicted in the early stages of its development. The spectrum and shape of the vibration signal stores information about the presence of characteristic defects of the rolling bearings. This information has specific features depending on the type of defect and the place where it was found. Such information is manifested by some features in the signal. One of such signs is the presence of asynchronous peaks in the spectrum. In addition, with developed defects, harmonics of such asynchronous peaks can be observed. The spectrum can contain both discrete peaks and blurred "humps" in which vibration energy is concentrated.

Let's move on to consider the signal itself, its parameters and the principles of its processing.

The signal that comes to a particular diagnostic apparatus is the oscillation of the object being monitored. Vibrodiagnostic is based on the measurement, analysis and processing of vibrations that occur during operation. Rolling and plain bearings can be a source of vibration in all machines. 
Vibration is not always the same. It can be deterministic or random. Accordingly, deterministic vibration is divided into periodic and non-periodic, and random - into stationary and nonstationary. Periodic deterministic vibrations are harmonic and polyharmonic [9].

Periodic vibration is characterized by the period of oscillations, frequency, frequency range and angular frequency.

Harmonic vibrations can be recorded by the sine or cosine function. Their argument is the phase of harmonic oscillations, which depends on the initial phase, time and frequency. Depending on the magnitude of the phase shift, harmonic oscillations are divided into in-phase and out-of-phase.

Polyharmonic vibrations occur when the same system is affected by different independent harmonic oscillations in the general case with different amplitudes and initial phase angles. The shape of polyharmonic oscillations is greatly influenced by the shift of the initial phases between harmonics. Beats can occur with such oscillations.

Harmonic analysis of periodic (polyharmonic) vibration is its representation in the form of the sum of harmonic oscillations, in which periodic oscillations are represented by a Fourier series and non-periodic - by the Fourier integral.

Values that characterize the intensity of periodic, including harmonic oscillations:

- peak values (largest and smallest values of the oscillating value);

- amplitude of oscillations (sum of absolute values of the largest and smallest peak values of the oscillating value);

- mean values: arithmetic mean and rms.

Vibroacoustic signals are stochastic oscillations, so when building their mathematical models using the methods of the theory of random processes. Currently, the most common model of vibroacoustic signals are stationary random processes with a discrete spectrum, which in the General case can be represented in a complex form in the following form:

$$
\xi(t)=\sum_{k=-\infty}^{\infty} \gamma_{k} e^{i 2 \pi f k}
$$

where $\gamma_{k}$ - independent equally distributed complex random variables in which the mathematical expectation $M\left[\gamma_{k}\right]=0$, and the variance $D\left[\gamma_{k}\right]=\sigma_{k}^{2}$.

The correlation function of process (1) is an almost periodic function and is equal

$$
R(\tau)=\sum_{k=-\infty}^{\infty} \sigma_{k}^{2} e^{i 2 \pi f k \tau} .
$$

From formula (2) it is seen that the variance of process (1) is equal

$$
D[\xi(t)]=R(0)=\sum_{k=-\infty}^{\infty} \sigma_{k}^{2} .
$$

The variance $\sigma_{k}^{2}$ of random amplitudes $\gamma_{k}$ of harmonic components with frequencies $f_{k}$ is called the spectrum of a random process (1).

The main statistical parameters for determining the state of the bearing are: mathematical expectation $M \xi(\tau)$, variance $D \xi(\tau)$, correlation coefficient $\rho$, asymmetry coefficient $\gamma_{3}$ and excess coefficient $\gamma_{4}$.

Mathematical expectation, average value - one of the main numerical characteristics of each random variable. It is a generalized concept of the average value of a set of numbers in the case when the elements of the set of values of this set have different "weight", price, importance, priority, which is characteristic of the values of a random variable [10].

The variance is a measure of the deviation of the values of a random variable from the center of distribution. Larger values of the variance indicate larger deviations of the values of the random variable from the center of distribution.
Correlation coefficient is an indicator used to measure the density of the relationship between performance and factor characteristics in the correlation-regression model with a linear relationship.

The asymmetry coefficient is a numerical characteristic of the probability distribution of a real random variable:

$$
k=\mu_{3} / \sigma^{3}
$$

The asymmetry $k$ of the theoretical distribution of probabilities of a random variable is the ratio of the central moment of the third order $\mu_{3}$ to the cube of the standard deviation $\sigma^{3}$.

The coefficient of excess is a numerical characteristic of the probability distribution of a real random variable. The coefficient of excess characterizes the "steepness", i.e., the rate of increase of the distribution curve compared to the normal curve. The excess $\gamma$ of the theoretical distribution is called the characteristic calculated by the following formula:

$$
\gamma_{4}=\frac{\mu_{4}}{\sigma^{4}}-3
$$

where $\mu_{4}$ - the central moment of the fourth order, $\sigma^{2}-$ the variance [6].

An important task is to choose the diagnostic parameter that would be most sensitive to changes in the state of the object and determine the high reliability of control. In the problems of vibration diagnostics of bearing units of electric machines, such a parameter is the excess coefficient of diagnostic signals, the use of which allows to determine such defects as lack of lubrication, skew, defect of the inner ring.

The excess method can also be used to study the condition of bearings. Excess is a diagnostic parameter that characterizes the deviation of the probability density of instantaneous vibration values from the normal distribution (Gaussian distribution). Excess is characterized by the coefficient of excess (5).

When micro- and macro-shocks appear in the bearing, the probability density curve takes on a more acute nature and the value of the excess coefficient can be used to judge the degree of development of the defect:

- $\quad \gamma_{k}<3$ - corresponds to a serviceable condition of the bearing;

- $\gamma_{k}>3$ - admissible operation of the bearing, but with its fast replacement;

- $\gamma_{k}<5$ - inadmissible operation of the bearing.

The method of excess is not sensitive to the speed of rotation and load of the bearing, and does not require knowledge of its geometric parameters. Also, the excess coefficient changes its value not only when shock pulses appear in the bearing, but also increases with the deterioration of the oil. The last fact allows to use this method and for sliding bearings. [9].

In probability theory and statistics, Student's t-distribution or t-distribution is a type of probability distribution that arises in the problem of estimating the expected value of a normally distributed population when the sample size is small. This distribution is the basis of the popular Student's t-test of statistical significance the difference between the mathematical expectations of the two samples, and the confidence interval of the difference between the expected values of the two samples.

The distribution density of the Student's t-distribution has a distribution density function given by the formula

$$
p(t)=\frac{\Gamma\left(\frac{v+1}{2}\right)}{\sqrt{v \pi} \Gamma\left(\frac{v}{2}\right)}\left(1+\frac{t^{2}}{v}\right)^{-\frac{v+1}{2}} .
$$

where $v$ is the number of degrees of freedom, $\Gamma(x)$ is the gamma function [7]. 


\section{Device structure}

The main content of vibrometry is the measurement of vibration parameters. Vibration of bodies is one of the most complex oscillatory processes, if we bear in mind all the degrees of freedom of the body and a wide range of oscillations, which can be non-periodic. These include steady-state, random, impulsive oscillations, etc. Vibration parameters: amplitude, frequency, peak-to-peak and a number of others - are measured using special off-the-shelf measuring devices and systems.

The general diagram of a device for measuring and analyzing vibration contains two main blocks (Figure 1): a vibration transducer and an electronic processing unit. The functional purpose of the first unit is to convert mechanical vibrations into an electrical signal. The principle of operation of piezoelectric transducers is based on the use of direct or reverse piezoelectric effects. The direct piezoelectric effect is the ability of some materials to form electric charges on the surface when a mechanical load is applied, the opposite is a change in the mechanical stress or geometric dimensions of the material sample under the influence of an electric field. As piezoelectric materials, natural materials are usually used - quartz and tourmaline, as well as artificially polarized ceramics based on barium titanate $\left(\mathrm{BaTiO}_{3}\right)$, lead titanate $\left(\mathrm{PbTiO}_{3}\right)$ and lead zirconate $\left(\mathrm{PbZrO}_{3}\right)$.

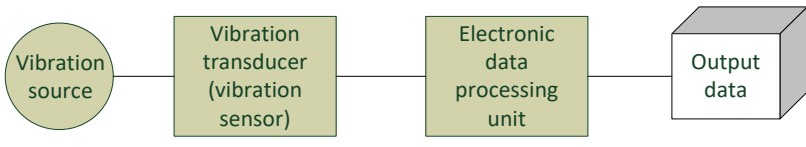

Fig. 1. Block diagram of the device

The second unit - the electronic processing unit - serves to "decode" the received signal. As a rule, an analog-to-digital converter is installed at the input of such blocks, and the main part of operations on the signal is performed already in digital form, which expands the functionality of the post-processing process, improves noise immunity and allows information to be output via an external interface.

When used in production, stationary vibrometers can be part of control systems as feedback sensors; for these purposes, some models of vibrometers have an analog output signal (usually voltage).

To obtain a comprehensive characteristic of the vibration process, a spectrum analyzer can be added to the measuring system. If the spectrum analyzer is multichannel, it can serve as the basis for a distributed vibration diagnostics system containing more than one vibration sensor.

The sensor is made on the basis of a piezoelectric sensing element [11] and is an absolute vibration transducer, that is, vibration is converted directly into electrical vibrations. The piezoelectric element is characterized by its resistance to overloads and a high natural frequency (from 30 to $50 \mathrm{kHz}$ ), therefore sensors with piezoelectric transducers are especially suitable for high-frequency processes in the range up to $20 \mathrm{kHz}$. The lower limiting frequency of such converters lies in the range of $0.5-10 \mathrm{~Hz}$. The sensor output signal is proportional to vibration acceleration, the maximum value of which is from 1 to $10 \mathrm{~m} / \mathrm{s}$.

The standard version of the piezoelectric element consists of a shielded metal disk on which a ceramic membrane is located. To connect to measuring equipment, leads are used that are connected to the thrust bearing. The principle of operation of the elements is based on measuring the capacity of the membrane. Signal transmission is carried out through the thrust bearing. The difference in discharges is recorded in the measuring instruments. Data can be processed and stored via terminals on the sensors.

The general view of the sensor is shown in Figure 2 . The sensor is made in a sealed plastic case of increased strength. The cable is connected to the vibration transducer, on the one hand, through the terminals connected to the thrust bearing. On the other hand, the cable is connected to the sound card of a personal computer via a 3.5 mini jack connector or a USB connector.

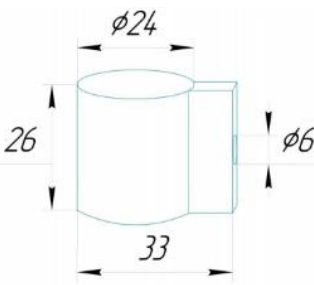

Fig. 2. General view of the sensor with linear dimensions

The sensor is installed on the measured object using an iron cobalt magnet, which is more resistant to mechanical stress, demagnetization and high temperatures than ceramic and neodymium magnets. The location of the magnet inside the insulated housing excludes its separation from the surface of the sensor, which greatly facilitates the process of measuring the vibration parameters.

The sensor is installed using a magnetic mount in the following sequence:

a) the sensor with a magnetic mount is installed on the object measurements;

b) the sensor is connected to the sound card of the personal computer using a cable.

During installation, make sure that the sensor is firmly attached (does not swing) on the measurement object. Otherwise, the measurement results may be inaccurate. Since the cable wire is shielded, it is allowed to cross the cable with other cables and conductors. It is not recommended to remove the sensor installed on the holding magnet by pulling the cable.

When solving the overwhelming majority of vibration metering problems, the measurement errors of vibration parameters can be $10 \ldots 15 \%$. The main share of the total measurement error in the measurement information conversion path falls on the sensor. The sensor, in comparison with other equipment, is in the most difficult operating conditions. In addition to vibration, as a rule, a number of other so-called influencing quantities act on it, which include: temperature, pressure, humidity, electromagnetic and electrostatic fields, radiation. Although measures are being taken to reduce the sensitivity of the sensors to influencing quantities, it is not possible to make it equal to zero.

\section{Results and discussion}

With the help of the Matlab programming environment, monitoring and analysis of vibration parameters, storage of the results of vibration studies are carried out [5]. The Matlab environment allows the use of spectral analysis of the measured vibration signal. This analysis is used to identify components in the frequency domain. An adequate area of its use is the study of various kinds of stationary signals consisting of the sum of components with a constant period. This method is based on the direct Fourier transform [6].

The specificity of signal analysis based on the Fourier transform is traced in the analysis of signals with a constant period (for example, harmonic). For this, a real signal:

$$
x(t)=A_{1} \cos \left(\omega t+\varphi_{1}\right)=a_{1} \cos \left(\omega_{1} t\right)+b_{1} \sin \left(\omega_{1} t\right),
$$

with a period $T$ are laid out in a Fourier series in multiple frequencies. This series can be presented in trigonometric form:

$$
\begin{gathered}
x(t)=\frac{a_{0}}{2}+\sum_{n=1}^{\infty} A_{n} \cos \left(n \omega_{1} t+\omega_{n}\right)= \\
=\frac{a_{0}}{2}+\sum_{n=1}^{\infty} a_{n} \cos \left(n \omega_{1} t\right)+b_{n} \sin \left(\omega_{1} t\right) \\
\frac{a_{0}}{2}=\frac{1}{T} \int_{-T / 2}^{T / 2} x(t) d t,
\end{gathered}
$$




$$
a_{n}=\frac{2}{T} \int_{-T / 2}^{T / 2} x(t) \cos \left(n \omega_{1} t\right) d t, b_{n}=\frac{2}{T} \int_{-T / 2}^{T / 2} x(t) \cos \left(n \omega_{1} t\right) d t,
$$

where $a_{n}, b_{n}$ are the coefficients.

In complex form:

$$
\begin{aligned}
x(t) & =\frac{1}{2}+\sum_{n=-\infty}^{\infty} A_{n}^{*} e^{j n \omega_{1} t}, \\
A_{n}^{*} & =\frac{2}{T} \int_{-T / 2}^{T / 2} x(t) e^{j n \omega_{1} t} d t,
\end{aligned}
$$

where $A_{n}^{*}$ is a complex coefficient.

For a non-periodic signal, the Fourier series is replaced by the Fourier integral:

$$
\begin{gathered}
x(t)=\frac{1}{2 \pi}+\int_{-\infty}^{\infty} S^{*}(\omega) e^{j \omega t} d \omega, \\
S^{*}(\omega)=\left|\int_{-\infty}^{\infty} x(t) e^{-j \omega t} d t\right|,
\end{gathered}
$$

Expression (12) is called the direct integral Fourier transform, expression (13) is called the inverse transform. In these transformations, instead of the amplitude, the concept of the spectral component $S^{*}(\omega)$ of the signal is used.

Currently, various discrete algorithms that implement the Fourier transform are widely used. After discretizing $x(t)$ and performing the appropriate substitutions $(\omega=2 \pi \mathrm{n} / \mathrm{N}$, where $N$ is the number of samples in the investigated time interval $(0 ; T)$ ), expressions (12) and (13) can be written in the following form:

$$
\begin{gathered}
S_{n}^{*}(\omega)=\frac{1}{N} \sum_{i=0}^{N-1} x_{i} e^{-j \frac{2 \pi}{N} n_{i}}, \\
x_{i}=\frac{1}{N} \sum_{n=1}^{N} S_{n}^{*} e^{j \frac{2 \pi}{N} n_{i}},
\end{gathered}
$$

The above system of equations requires $N^{2}$ computational operations. Due to the fact that the coefficients in expression (15) are conjugate, it becomes possible to partition the original matrix into matrices with the number of elements not exceeding $\log _{2} N$, each of which contains 2 nonzero numbers. This transformation is called the Fast Fourier Transform. Such a mathematical apparatus makes it possible to conduct deeper studies of equipment vibration, to localize the signal in the frequency domain, which makes it possible to represent the signal in the form of separate additive components. These components have characteristic features for each individual defect, which allows not only to integrally assess the technical condition of the equipment, but also to identify the type of defect with a certain degree of reliability.

\section{Conclusion}

Vibration diagnostics is now widely used, since vibration processes sufficiently fully reflect the technical condition of many parts and assemblies. An important task is to choose the diagnostic parameter that would be most sensitive to changes in the state of the object and determine the high reliability of control Therefore modern methods of vibroacoustic diagnostics were investigated, diagnostic signs of characteristics of signals are presented, their basic properties, ways of their use at research of a vibro signal are opened. The principles on which they work are described and the characteristics of the signal they use are indicated.

The paper proposes a diagram of a vibration analysis device, which consists of a sensor for measuring vibration, the principle of operation of which is based on the use of a direct piezoelectric effect. The output signal of the sensor goes to a personal computer or any other device with the Windows operating system, where a spectral analysis of the measured vibration signal is carried out using a Matlab-based diagnostic program.

\section{References}

[1] Babak V., Beregun V., Krasilnikov A.: Methods and means of vibrodiagnostics of units of cogeneration installations. Scientific Proceedings of STUME 1(216), 2017, 141-145.

[2] Barkov A. V., Barkova N. A.: Vibration diagnostics of machines and equipment. Vibration analysis. SMTU, Sankt-Petersburg 2004

[3] Barkova N., Barkov A., Grishchenko D.: Vibration diagnostics of equipment units with gas turbine engines. Vibroengineering Procedia 25, 2019, 89-94.

[4] Beregun V. S., Krasilnikov A. I.: Research of excess kurtosis sensitiveness of diagnostic signals for control of the condition of the electrotechnical $\begin{array}{llll}\text { equipment. Tekhnichna elektrodynamika 4, 2017, 79-85 } & \end{array}$ [http://doi.org/10.15407/techned2017.04.079].

[5] Chernykh I. V: Modeling of Electrical Devices in MATLAB, SimPowerSystems and Simulink. DMK-Press, Moscow 2008

[6] Goldin A. S.: Vibration of rotating machines. Mashinostroyeniye, Moscow 1999.

[7] Gorban I. I.: Probability theory and mathematical statistics for scientists and engineers. National Academy of Sciences of Ukraine, Kyiv 2003.

[8] Kozochkin M. P., Kochinev N. A., Sabirov F. S.: Diagnostics and monitoring of complex production processes using measurement of vibration-acoustic signals. Measurement techniques 49.7, 2006, 672-678.

[9] Petrukhin V. V., Petrukhin S. V.: Fundamentals of vibrodiagnostics and vibration measuring instruments. Infra-Inzheneriya, Moscow 2010.

[10] Senyo P. S.: Probability theory and mathematical statistics. Znannya, Kyiv 2007.

[11] Sharapov V. M., Musienko M. P., Sharapova E. V.: Piezoelectric Sensors, Tekhospfera, Moscow 2006.

[12] Stakhova A., Kvasnikov V.: Structure Construction of Acoustic Emission System for Diagnostic of Friction Clusters. IEEE 13th International Scientific and Technical Conference on Computer Sciences and Information Technologies (CSIT) 1, 2018, 64-67.

\section{Ph.D. Eng. Anzhelika Stakhova}

e-mail: sap@nau.edu.ua

Doctoral student at the National Aviation University (NAU). Associate Professor of Computerized electrical systems and technologies department NAU. Main scientific direction - systems for measuring mechanical quantities, the control and forecasting of the technical condition

http://orcid.org/0000-0001-5171-6330

\section{Prof. Volodymyr Kvasnikov}

e-mail:kvp@nau.udu.ua

President of Engineering Academy of Ukraine, Head of Computerized electrical systems and technologies department (NAU).

Main scientific direction - development of methods and instruments for measuring mechanical quantities and metrological support for measurement processes.

http://orcid.org/0000-0002-6525-972
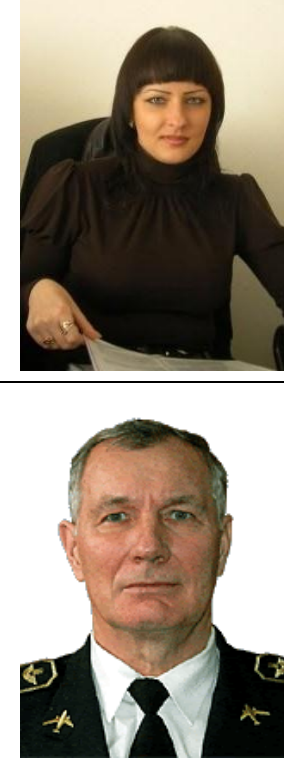

otrzymano/received: 8.05 .2021 